\title{
A construção de um complexo posicionar-se e o fazer etnográfico na Diáspora Africana: o caso dos estudantes angolanos de Lins-SP
}

The construction of a positioning and ethnographic complex in the african diaspora: the case of angolan students from Lins-SP

Cauê Gomes Flor ${ }^{1}$

Resumo: Entre os anos de 2004 a 2015 a cidade de Lins -SP recebeu, proporcionalmente, o maior fluxo de estudantes africanos do interior paulista. Lá residiram e estudaram cerca de 140 estudantes provenientes dos Países de Língua Oficial Portuguesa (Palop): Angola, Cabo Verde, São Tomé \& Príncipe, Moçambique e Guine Bissau. No entanto, são preponderantes os jovens provenientes de Angola, cerca de 120, sendo, os únicos que se enunciam enquanto comunidade angolana. Ao enunciar esse discurso, os estudantes angolanos agenciam e negociam um conjunto de representações, afirmam diferenças e promovem processos de identificação. Observa-se, assim, a emergência de um posicionamento de caráter étnico protagonizado pelos estudantes expressão da atribuição adscrita da negrura, histórica e cotidianamente aos povos de origem africana em sua experiência coletiva. Os estudantes em sua experiência coletiva no Brasil passam por um processo de racialização e em reação a essa negação, produzem, por meio de um processo de etnicização, um posicionamento ético e político que, por sua vez, articula de forma interseccionada ambas as clivagens, raça e etnia. Isto é, tão importante quanto à intersecção e articulação de ambas as clivagens é explorar o processo, o "como" os estudantes realizam esse agenciamento e negociação.

Palavras chave: Diáspora Africana. Diferença. Etnia. Linguagem. Raça.

Astract: From 2004 to 2015, the city of Lins -SP received, proportionally, the largest flow of African students from São Paulo countryside. About 140 students from the Portuguese-speaking Countries (Palop) resided and studied there: Angola, Cape Verde, Sao Tome \& Principe, Mozambique and Guinea Bissau. However, there are preponderant young people from Angola, around 120, being the only ones that speak out as Angolan community. In stating this discourse, angolan'sstudents agency and negotiate a set of representations, affirm differences and promote identification processes. Thus, there is the emergence of a position of ethnic character led by students expression of the ascribed attribution of blackness, historically and daily to people of African origin in their collective experience. Students in their collective experience in Brazil go through a process of racialization and, in reaction to this denial, produce, through a process of ethnicization, an ethical and political position that, in turn, intersects both cleavages, race and

\footnotetext{
${ }^{1}$ Doutorado em Ciências Sociais Pela Universidade Estadual Paulista Júlio de Mesquisa Filho - UNESP. E-mail: caueflor@gmail.com. Orcid: https://orcid.org/0000-0002-6306-0612
} 
ethnicity. That is, just as important as the intersection and articulation of both cleavages is to explore the process, the "how" students perform this agency and negotiation.

Keywords: African Diaspora. Difference. Ethnicity. Language. Race.

\section{Introdução - Como e porque o Brasil apresenta-se como destino para os estudantes africanos?}

Pode-se dizer que a vinda de estudantes angolanos para o Brasil é um aspecto recente da história do país. Fora apenas após a independência de Angola, em 1975, que viera a ocorrer uma mudança no eixo do fluxo dos universitários angolanos. Nesse novo contexto, pós-colonial, profundamente marcado pelas demandas ideológica da Guerra Fria e da luta anticolonial, os estudantes angolanos deixariam de concluir os seus cursos superiores, exclusivamente, em centros universitários portugueses, para abriram uma nova fronteira acadêmica, realizando sua formação superior nos países do leste europeu e em Cuba. É só a partir do final da década de 1990 e, sobretudo, início do século XXI, não gratuitamente, que as universidades brasileiras passam a chamar a atenção desse significativo fluxo estudantil africano. Se, por um lado, as universidades brasileiras tornavam-se cada vez mais atraentes em razão da facilidade de intercâmbio devido a língua (grifo nosso) portuguesa aqui falada, de outro, a abertura dessa nova fronteira estudantil pelos jovens angolanos é fruto, também, de um intenso esforço manifesto da política externa brasileira (entre 2004 à 2015) em cativá-los a conduzir seus estudos no Brasil ${ }^{2}$ (FONSECA, 2009).

\footnotetext{
${ }^{2}$ De fato, o diálogo entre Brasil e África é de longa data histórica e, certamente a escravidão é a marca que fundamenta e deflagra o início desse profícuo e, por vezes, doloroso "diálogo atlântico". De acordo com o cientista político José Flavio S. Saraiva (1998, 2002), as relações entre Brasil e África no período contemporâneo (a partir de 1930) podem ser compreendidas sobre quatro momentos históricos que marcam as políticas externas estabelecidas entre Brasil e o continente africano. $\mathrm{O}$ autor estabelece os seguintes períodos da política africana brasileira: o primeiro, o do "esquecimento", o "afastamento deliberado" da África. Período que transcorreu entre as décadas de 1930 a 1946. O segundo, inscrito no período circunscrito entre 1946 a 1961, denominada de "o Brasil e o renascimento africano". O terceiro momento é nomeado por Saraiva (1998) como "avanços e recuos nas relações Brasil-África", que está contido no período de 1961 a 1969. E o quarto, "a reafirmação da política africana". Momento que se iniciou em 1969, no qual o Brasil retoma o diálogo com África, e têm como marca os acordos ancorados em interesses econômicos e socioculturais, movimento que continua em ascensão até os dias de hoje. Um aspecto importante da perspectiva historiográfica concebida por Saraiva (1998), é que este diálogo é um movimento pendular, ora há uma estreita aproximação, ora um distanciamento profundo. Também no interior da formulação do autor é possível observar três grandes marcos históricos, três grandes políticas imigratórias que se detiveram no trato da vinda de africanos para o Brasil: a escravidão, a política de branqueamento e os recentes acordos (políticos, sociais, culturais e econômicos) bilaterais. Ainda segundo o autor, a recente política brasileira, embora agora interrompida para o continente africano viria a se assentar nos seguintes argumentos: i) o retraçar dos caminhos trilhados por diplomatas brasileiros, a partir do início do século XX, como forma de revitalizar a imagem do Brasil como poder tropical, mas que um dia também fora colonial. De modo a fortalecer a ideia de uma civilização moderna nos trópicos. No intuito de demonstrar à
} 
Além desse fatores, soma-se também as profundas transformações substanciais e, não menos relevantes, que ocorreram nos últimos vinte anos, tanto no lugar que é atribuído aos povos, às culturas e tradições de origem africana na formação da sociedade brasileira, quanto na maneira como a identidade nacional é abordada nos debates e discussões que se dedicam à investigação das relações raciais na contemporaneidade. Desde as primeiras publicações do Projeto UNESCO (MAIO, 1999), protagonizadas, na década de 1950, por Florestan Fernandes, Roger Bastide e Virgínia Bicudo ${ }^{3}$, o ideário de nação brasileira, elaborado por Gilberto Freyre (2008), propagado pelo Estado Novo (1937-1945) e em vigor até o final da ditadura militar (1964-1985), vem sendo questionado. Durante as décadas de 1980 e 1990, coube ao "movimento negro", como o Movimento Negro Unificado (GUIMARÃES, 2002), organizado em torno de uma solidariedade política pautada na consciência da racialização da experiência coletiva e fundamentada na ideia de uma identidade e de uma cultura comuns, denunciar a íntima relação entre desigualdades sociais e adscrições raciais presentes na sociedade brasileira. Esses movimentos sociais negros, por meio desse modelo de identidade e de cultura, não só lutaram por direitos, mas contribuíram para a desconstrução da suposta natureza homogênea, harmônica e não conflituosa da sociedade brasileira (COSTA, 2006; HOFBAUER, 2006).

Segundo Costa (2006), foi durante a participação brasileira na "III Conferência Mundial das Nações Unidas Contra o Racismo, Discriminação Racial, Xenofobia e Intolerância Correlata”, realizada pela ONU em Durban, África do Sul, em 2001, que os movimentos sociais negros, por meio de "uma compreensão da história nacional muito distinta daquela alardeada pelos nacionalistas mais contundentes" (COSTA, 2006, p. 145), produziriam um solo fértil para o desenvolvimento e difusão de uma plataforma antirracista. Um dos maiores, se não o maior efeito dessa plataforma, foi a alteração da Lei de Diretrizes e Bases da educação brasileira (LDB), em decorrência da Lei no 10.639/03 e seu desdobramento prático, presente nas Diretrizes Curriculares

exitosa e harmoniosa experiência racial, de uma civilização moderna que um dia fora colônia, mas que hoje superou sua metrópole; ii) a valorização da força e presença das culturas africanas na formação da sociedade brasileira e, portanto, da identidade nacional; iii) a ideia de que o Brasil goza de um prestígio natural junto aos países.

${ }^{3}$ Embora, não amplamente citado, mas também de competência do Projeto UNESCO, Estudo de atitudes raciais em São Paulo (1945-1955), de Virgínia Bicudo, é um dos primeiros trabalhos a investigar, naquele momento, a relação entre brancos e pessoas de cor em São Paulo. Ver: GOMES, Janaina D. Os Segredos de Virgínia: estudos de atitudes raciais em São Paulo (1945-1955). São Paulo. Tese (doutorado) Faculdade de Filosofia, Letras e Ciências Humanas da Universidade de São Paulo (USP). 2013. 
Nacionais para a Educação das Relações Raciais e para o Ensino de História e Cultura Afrobrasileira e Africana (BRASIL, 2003, 2004; SILVÉRIO; TRINDAD, 2012).

Tais transformações, articuladas à política externa de reafirmação da política externa africana ${ }^{4}$, estabeleceram condições profícuas para a celebração de novos acordos, não só econômicos, mas também de educação e cultura entre o Brasil e os países do continente africano, em particular aqueles de língua oficial portuguesa (Palop). Segundo os dados disponibilizados pela Divisão Educacional do Ministério das Relações Exteriores ${ }^{5}$ (MRE), durante as duas últimas décadas (2000-2019), vieram para o país cerca de 7991, entre instituições publicas e privadas, estudantes proveniente da África mediante o Programa Estudante Convênio Graduação ${ }^{6}$ (PEC-G). Desse contingente, entretanto, é clara a preponderância de jovens dos países Palop, com destaque para Guiné-Bissau, Angola e Cabo Verde.

Entre as Instituições de Ensino Superior (IES) particulares do Estado de São Paulo que receberam estudantes africanos durante o período, destaca-se o Centro Universitário de Lins (Unilins). Entre 2004 -2015, a pequena cidade de Lins recebeu, proporcionalmente, o maior fluxo de africanos do interior paulista. Lá residiram e estudaram na Unilins um número permanente ${ }^{7}$ de ao menos 140 estudantes naturais dos mais diversos pertencentes ao Palop: Angola, Cabo Verde, São Tomé \& Príncipe, Moçambique e Guine Bissau. No entanto, foram preponderantes os jovens provenientes de Angola, com contingente permanente de ao menos 120 estudantes entre $2004 \mathrm{e}$ 2015, sendo também os únicos que enunciavam-se, apesar da presença de outras estudantes de outras nacionalidade, enquanto comunidade, a angolana.

\footnotetext{
${ }^{4}$ Outro autor que também se debruça de forma sistemática sobre a história da relação Brasil África é Dávila (2011) em seu texto - Hotel Trópico: O Brasil e os desafios da descolonização africana, 1950-1980. Nesta obra o autor se preocupa em perceber como os diplomatas e intelectuais brasileiros que transitaram por países africanos exploraram a noção cunhada por Gilberto Freyre denominada de "lusotropicalismo". "O termo cunhado por Freyre sugeria que os portugueses possuíam uma maneira especial de viver nos trópicos, caracterizada pela mistura racial e pela afinidade com negros: O Brasil seria a melhor exemplo desse ideal lusotropical" (DÁVILA, 2011, p.12). O lusotropicalismo que encontra a sua forma ideológica mais bem acabada na chamada "democracia racial", seria a marca singular do recente processo de formação da nação brasileira. $\mathrm{O}$ autor afirma que os diplomatas brasileiros buscaram acentuar a sua herança africana presente na cultura brasileira em suas missões a África.

${ }^{5}$ Ministério das relações exteriores:http://www.dce.mre.gov.br/PEC/G/historico/introducao.php

6Segundo o MRE o programa PEC-G foi criado oficialmente em 1965 pelo Decreto $\mathrm{n}^{\circ} 55.613$ e, atualmente regido pelo Decreto $\mathrm{n}^{\mathrm{o}} 7.948$, oferece a estudantes de países em desenvolvimento com os quais o Brasil mantém acordo educacional, cultural ou científico-tecnológico a oportunidade de realizar seus estudos de graduação em Instituições de Ensino Superior (IES) brasileiras.

${ }^{7}$ Apesar de minha insistência junto a Unilins ao acesso dessa informações, nunca obtive a oportunidade de tabular o número total de estudantes africanas que passaram pela instituições ao longo de todos esses anos.
} 
Mas, como e por que uma modesta cidade no interior de São Paulo tem atraído para a sua pequena autarquia municipal de ensino esse contingente proporcionalmente tão expressivo de estudantes africanos? Após 44 anos (e, com alguns intervalo, 27 anos de Guerra Civil) de sua independência de Portugal, Angola ainda enfrenta um processo permanente de (re)construção. Diante dessa conjuntura, empresas brasileiras, no fundo, grandes conglomerados passaram a investir massivamente da reconstrução país. O Grupo Camargo Corrêa, a Construtora Andrade Gutierrez, a Sonangol (a principal empresa petrolífera de Angola) e sua representante no Brasil a Siano \& Rego são alguns dos exemplos que podemos citar com interesses no aprofundamento das relações Brasil-Angola afim de estabelecer não só contratos para (re)construir o país, mas também para a sedimentação de novos negócios no continente.

A exemplo desse interesse, a primeira turma de estudantes angolanos que vieram cursar suas graduações na Unilins foi arregimenta pela Fundação Eduardo dos $\operatorname{Santos}^{8}$ (FESA), os primeiros egressos fizeram o vestibular já no Brasil, sendo a primeira turma constituída em 2004 por 70 estudantes. Segundo notícia divulgada: ${ }^{9}$

\begin{abstract}
A Unilins recebeu, na tarde da última quinta feira, diversas autoridades para anunciar oficialmente a chegada de aproximadamente 70 estudantes angolanos, que irão integrar o quadro de alunos da instituição. Eles serão matriculados nos cursos de Engenharia (todas as áreas), Sistemas de Informação, Serviço Social e Enfermagem. [...] Os angolanos devem chegar ao campus até o final do mês de março. O motivo da reunião marcada pela direção da Unilins consiste em apresentar às autoridades e à imprensa a importância que esse convênio tem para a cidade. Além de representar um avanço nas relações internacionais que envolvem Instituições de Ensino Superior, os novos alunos, que inicialmente ficarão hospedados em hotéis da cidade, devem proporcionar um significativo aumento no giro econômico da cidade.
\end{abstract}

Desde então, a cidade recebeu, todo ano, um fluxo contínuo de jovens angolanos. Os estudantes cursam, na sua maioria, graduações ligadas às áreas das Ciências Exatas e Ciências Sociais Aplicadas, sobretudo Engenharias Civil, Elétrica e Mecânica. Muito embora o PEC-G seja vinculado ao MRE, responsável pelo pagamento das bolsas cujo valor é entre U\$300,00 (trezentos dólares) e U\$500,00 (quinhentos dólares), uma parte significativa dos estudantes angolanos de Lins, principalmente aqueles que vieram nesse momento inicial, são beneficiários de outra

\footnotetext{
${ }^{8}$ A Fesa apresenta-se como uma organização da sociedade civil, que tem em seus objetivos atuar como parceira do governo angolano nas diferentes vertentes de desenvolvimento. Afirma-se como uma instituição filantrópica, apartidária de caráter técnico cientifico, cultural e social, sem fins lucrativos e de educação ilimitada. Ver: http://www.fesa.og.ao/fundacao/apresentacao.htm . Acesso em março de 2014.

${ }^{9}$ Acesso em Junho de 2012. http://www.unilins.edu.br/noticias/index.php?idnoticia=888
} 
qualidade de bolsa. Ao indagar os estudantes, responderam-me que suas bolsas eram pagas por grandes multinacionais brasileiras que, então, investiam na reconstrução país. Andrade Gutierrez, Camargo Correia eram as empresas que ofereciam a maioria das bolsas de estudos que atraem jovens angolanos a vir ao Brasil. Suas bolsas chegavam ao valor de U\$1500,00. Em contrapartida, esses jovens deveriam prestar serviços a estas empresas depois de seu retorno. Isto é, a própria escolha dos cursos nessas áreas estava articulada com o financiamento dos estudos e com a ideia de retorno a Angola para contribuir nas empresas.

A Unilins, diante da nova demanda, passou a realizar o seu vestibular também em Angola. Por meio de um conjunto de parcerias firmadas entre a Unilins e Centros Universitários Angolanos, o processo seletivo da faculdade brasileira passou a ser realizados já no ano de 2005. O primeiro vestibular da instituição contou com a participação de cerca de 11.000 inscritos, sendo endereçado (conforme o edital mais recente de setembro de 2011) à alunos estrangeiros não residentes no Brasil que possuíam Certificado de Conclusão de Ensino Médio ou documento equivalente. O vestibular é desde então realizou-se em Luanda na Universidade Metropolitana de Angola (UniMetro). Entre 2004 e 2015, a Unilins estabeleceu uma política estudantil específica para os estudantes africanos, especialmente, para os angolanos, com comissões específicas que tinham a responsabilidade de fazer visitas sazonais (no mínimo duas vezes ao ano) a Angola e contando com a presença de assistentes sociais orientados a assistir esses estudantes e um conjunto de informações sobre as benesses da graduação no Brasil foram amplamente divulgadas.

Nesse sentido, esse trabalho procura tematizar de forma específica as experiências desses jovens estudantes angolanos na sociedade brasileira. Compreendemos que ao enunciar esse discurso de pertencimento (comunidade angolana), os estudantes africanos agenciam e negociam um conjunto de representações, afirmam diferenças e promovem processos de identificação. Observa-se, assim, a emergência de um tipo de posicionamento de caráter étnico protagonizado pelos estudantes que, como pretendemos demonstrar, é uma reação a atribuição adscrita da negrura ${ }^{10}$ (FANON 2008), histórica e cotidianamente aos povos de origem africana em sua experiência coletiva.

\footnotetext{
${ }^{10}$ A noção de negrura para Fanon (2008) emerge de sua reflexão sobre a questão colonial, tanto objetiva, e, sobretudo subjetiva. Esta reflexão toma forma no seu texto de 1952: Pele negra mascaras brancas, em que Fanon apropria-se de problemas e pensadores clássicos da Filosofia, Sociologia e Psicologia para construir uma explicação sofisticada para as alienações psíquicas causadas pelo colonialismo. Negrura é o termo utilizado pelo autor para denominar o processo de negação da humanidade do colonizado (negro). A criação do e racialização do Outro, bem como estranhamento daí
} 
Dito de outro modo, os estudantes em sua experiência coletiva no Brasil passam por um processo de racialização, que segundo suas narrativas (como veremos a seguir), ocorre desde o momento em pisam nos aeroportos brasileiros. Em reação a essa negação, os estudantes produzem, por meio de um processo de etnicização ${ }^{11}$, um posicionamento étnico e político (GUSMÃO, 2006, 2008, 2013) que, por sua vez, articula de forma interseccionada essas duas clivagens, raça e etnia. Isto é, tão importante quanto à intersecção e articulação de ambas as clivagens é o processo, o como (grifo nosso) os estudantes realizam esse agenciamento e negociação. Investigar e explorar o como e de que forma esses estudantes estão (re)construindo através de complexos processos culturais figuras de identidade e diferença, é o objetivo deste artigo. Ao nos concentrarmos, portanto, na produção da diferença e identidade, vale aqui também chamar a atenção que nos apoiaremos nos consensos e dissenso entre os enfoques antropológicos e a perspectiva pós-colonial (HOFBAUER, 2009). Como Hofbauer sugere (2017, p. 61) “o enfoque antropológico quanto o pós-colonial permitem-nos acesso a dimensões importantes dos fenômenos socioculturais, acredito ser necessário investir no desenvolvimento de uma perspectiva analítica plural(izada)".

O artigo está divido em três partes. Após esta introdução, iniciamos a nossa reflexão a partir da função soque (sinal diacrítico) para a constituição do senso de pertencimento étnico dos estudantes angolanos. Mas, mais do que tratarmos da função desse sinal diacrítico, nos preocupamos em etnografar como o sotaque denota a profícua agência dos estudantes como produtores de significado (sujeitos significantes). Na segunda seção do artigo, precedida por um prólogo, continuamos a investir na agência dos estudantes como sujeito significante, acentuamos, entretanto, a relação entre o sotaque e o jogo de linguagem e representação afim de tornar inteligível que tal complexo posicionar-se é tanto político quanto epistemológico. No terceira seção, nossa conclusão, agora antecedida por um epílogo, sustento que a agência dos estudantes e, sobretudo, o modo como eles articulam a sua diferença e enunciam o seu senso de pertencimento podem ser descritos a partir do conceito de diáspora africana, particularmente, aquele formulado por autores pós-coloniais, tais como Paul Gilroy e Stuart Hall. Ao enunciarem-se como a comunidade angola

resultante, retiram do colonizado a possibilidade de ser visto (e consequentemente, de se ver) como expressão universal do gênero humano. Isto é a grosso modo o que define o conceito, porém, são as formas pelas quais essas relações se expressam que são objeto de nossa reflexão.

${ }^{11}$ Utilizamos o termo etnicização e não etnicidade em função do contexto e constituição do tipo de pertencimento elaborado pelos estudantes. Uma vez que, em Angola, é possível identificar três grandes grupos étnicos: ovimbundos, kimbundos e bacongo. 
e agenciarem a sua identidade cultural, os estudantes angolanos de Lins tem sido eficientes em rejeitar os esquemas epistemológicos racializados de representação do cotidiano brasileiro e produzir formas de pertencimento e diferença que a extrapolam.

\section{O sujeito significante e a estratégia do sotaque}

Entre as minhas idas e vindas a Lins -SP um marcador de pertencimento (sinal diacrítico) em especial tornou-se recorrente nas narrativas dos estudantes angolanos, a saber, a linguagem, mais detidamente, o sotaque. Segundo os estudantes, a comunicação, de forma geral, representou, contraditoriamente, a um só tempo, tanto uma grande dificuldade, fonte de inúmeros mal entendidos e constrangimentos, quanto uma exímia aliada para se travar tensas relações cotidianas na sociedade brasileira. O sotaque tornou-se uma diferença que marcaria uma estratégia étnica e agenciado com esse fim em várias situações ordinárias da vida dos jovens angolanos de Lins - SP.

A título introdutório de meu argumento, transcrevo agora a narrativa de Vicente ${ }^{12}$, meu interlocutor, ${ }^{13}$ :

Só qui é bom começa dize qui... o rapais que viveu essa história já não tá no Brasil porque envolve polícia. É qui, é uma feistaqui uns colegas foram, eu não fui esse día, era uma feista aqui pertinho, em Guaiçara. A genti tinha acabado de chega, nu fazia um âno e a gente foi, você sabe como é qui é o nosso sutaque é bem diferente do vosso. Mas quando você em um lugar, você acha que tudo lá é bunito, e gente queria fala quinem brasileiro... "ah! que isso..."; "legal"; "na boa". Assim né! Só que na feesta tinha uns cara que mexia com coisa errada. E policia já tinha ouvido comenta e tudo maiss. Aí depois de um tempo chego a polícia né na festa. Pego todo mundo crio àquela confusão e eless não tavam proguntando direito que vc... só tavam enquadrando já. E tinha um colega nosso... Alguns conseguiram fuji, dos nosso amigos, brasileiros. Só que um colega nosso que acabo ficando. A policia chego pra ele e ele tava falando: "ow não fiz nada mano"; " que isso mano"; "não faz isso comigo"; " na boa mano". Aí chego um outro amigo que viu que ele já tava com a policia. E foi falando: " fala bem, fala bem, a grita com ele"; "fala bem o portugueis". Ai quando ele se tocou, ele começo a fala: " eu não fiíz nada sério, eu só vim pra feesta e tudo maiss". Ai os policias perguntaram: você não é brasileiro? Então ta bom fica ai. Então foi o suficiente para apaziguar os ânimos. Ou seja, quando ele tentou fala feito brasileiro eles enquadraram ele. (VICENTE, ENTREVISTA, OUTUBRO, 2012).

A narrativa de Vicente enuncia um dos problemas enfrentados pelos jovens angolanos, principalmente os homens, no contexto brasileiro: o tratamento policial truculento. Sim,

\footnotetext{
${ }^{12}$ Narrativa cedida ao pesquisador ainda em outubro de 2012.

${ }^{13}$ As palavras e freses que seguem apresentam erros ortográficos e de concordância propositalmente. De forma a exprimir aspectos fonéticos da pronúncia do português falado peles estudantes angolanos.
} 
discutiremos a ação policial, elemento essencial a nossa reflexão, mas, mais do que isso, interessanos abordar não só a estratégia utilizada pelos estudantes afim de tangenciar o tratamento, mas a maneira como a mesma é articulada. Assim, "Eu não fí́z nada, sério, eu só vim pra feesta e tudo mais...", é o elemento que emerge como centro de nossa análise. Tal sentença, enunciada no diálogo travado com o policial, gostaríamos de sugerir, produz um efeito de diferenciação, um posicionamento intencional. Mas, diferenciação em relação à que, ou em nosso caso, quem? E, por quê?

A diferença implicitamente no jogo de linguagem e significação (semântico) que o jovem angolano articula durante a circunstância relatada na narrativa é a categoria negro. É por meio dessa categoria que o jovem produz um efeito de diferença, um posicionando enquanto diferença cultural. Segundo Bhabha (2013[1994], p. 208), a diferença cultural, não tratar-se-ia da aquisição ou acumulação de "um saber cultural adicional, mas é a momentosa, embora momentânea, extinção do objeto da cultura como reconhecível no perturbado artifício da significação, na extremidade da experiência". Isto é, o estudante torna-se diferença cultural no exato momento do presente em que deixa de ser objeto reconhecível da cultura e toma a enunciação para si, torna-se sujeito significante. É também nessa momentosa, embora momentânea extinção de sua objetividade cultural em que ocorre um ruído, uma hesitação na significação responsável por adiar o significado, precisamente a différance ${ }^{14}$, uma tomada de posição no campo da cultura. No exato momento em que o estudante diz: “eu não fiíz nada sério, eu só vim pra feesta e tudo maiss”, o efeito de diferença é produzido, o jovem diferencia-se do "negro brasileiro", operando um processo de etnicização e marcando o seu pertencimento ao grupo - os angolanos. Vale aqui dizer que, classificamos tal processo, como etnicização em razão do fato de que muitos desses estudantes provinha de origens regionais e étnicas diferentes no seu contexto nacional. O senso de pertencimento aqui produzido

\footnotetext{
14 “[...] essas diferenças esse efeitos de diferença” (Derrida, 1981, 1982). Não se trata da forma binária de diferença do que é absolutamente o mesmo e o que é absolutamente "Outro". É uma onda de similaridades e diferenças, que recusa a divisão em oposição binária fixas. Différance caracteriza um sistema em que "cada conceito [ou significado] está inscrito em uma cadeia ou em um sistema, dentro do qual ele se refere ao outro e aos outros [significados], através de um jogo sistemático de diferenças" (Derrida, 1972). O significado aqui não possui origem nem destino final, não pode ser fixado, está sempre em processo e "posicionado" ao longo de um espectro. Seu valor político não pode ser essencializado, apenas determinado em termos relacionais. As estratégias de différance não são capazes de inaugurar formas totalmente distintas de vida (não funcionam segundo a noção de uma "superação dialética totalizante"). Não podem conservar as formas de vida tradicionais. Operam melhor dentro daquilo que Homi Bhabha denomina de "tempo liminar" das minorias (Bhabha,1997). Contudo, a différance impede que qualquer sistema se estabilize em uma totalidade inteiramente saturada (COSTA, 2006, p. 60-61).
} 
e os sinais diacríticos utilizados para caracterizá-lo, a princípio põe-se para além das delimitações regionais e/ou étnicas salutares no contexto nacional. Em outros palavras, as intersecções entre raça, etnia e nação toma contornos específicos em meio a processos históricos e culturais contingentes (BRAH, 2006).

Entretanto, se, o sotaque marca, num primeiro plano, uma diferenciação em relação ao “negro brasileiro”, num plano mais profundo, poderíamos dizer também que tal estratégia étnica desestabiliza, para os fins dos argumentos que estamos desenvolvendo, a raça como signo, isto é, "significante produzido no seio de uma estrutura, onde o estado e os grupos que com ele se identificam produzem e reproduzem seus processos de instalação em detrimento de e a expensas dos outros que este mesmo processo de emergência justamente secreta e simultaneamente segrega" (SEGATO, 2005, p. 10). "Raça" aqui funcionaria como uma categoria representacional, responsável por estabelecer um regime racializado de representação, capaz de, arbitrariamente, inscrever o corpo dos estudantes em meio aos seus dispositivos de poder e regulação. Tomemos com atenção, ainda que superficialmente, a ação truculenta do policial para com o jovem angolano. Embora os hábitos racistas orquestrados por policiais não sejam reconhecidos publicamente pela corregedoria da instituição militar e muito menos pelo oficiais da corporação, esse conjunto de práticas estereotípicas, recorrente e grosseiramente chamadas de "tirocineo", são patentes ao corpo da polícia militar do Estado de São Paulo no trato do "cidadão de cor". Ao agenciar o sotaque e tornar-se sujeito significante, os estudantes estão intencionalmente, deslocando a significação fixadora exercida sobre ser negro que o processo de racialização de sua experiência coletiva presente na prática policial os outorga: "você não é brasileiro? Então ta bom fica ai".

Guimarães (2002), citando caso análogo, ao investigar o insulto racial argumentaria que tal gesto ofensivo deve ser compreendido como instrumento de humilhação, sua lógica reside justamente em demarcar o afastamento do insultador em relação ao insultado, remetendo este último para o terreno da pobreza, da anomia social, da sujeira e da animalidade (GUIMARÃES, 2002, p.173). A ideia de um preconceito racial dissimulado e que se faz na intimidade (SCHWARCZ, 1998), por meio de anedotas de fundo preconceituoso presente na narrativa de Vicente, é o mesmo elemento semântico presente também nas práticas policiais.

Em outras palavras é reconhecendo as nuanças de como o "racismo a brasileira" se expressa em práticas da vida ordinária que poderemos enunciar mais adequadamente a força do sotaque enquanto marcador de diferença articulado como sinal distintivo que podemos extrair mais uma 
determinação encerrada e subscrita nesse complexo posicionar-se produzido pelos estudantes angolanos. O "sotaque "não só conduz a um efeito que diferencia etnicamente o jovem angolano "negro" do "negro brasileiro", mas, também e, sobretudo, é um posicionamento em relação a sociedade racialmente estruturada brasileira, que tende a perceber o indivíduo "negro" a partir do “estereótipo do agressor”, racializando sua experiência (SILVÉRIO, 2013).

Portanto, os seguintes comentários, sugerimos, devem ser realizados acerca da diferença (a categoria negro) implícita no jogo de linguagem e significação que etnografamos. O primeiro, retoricamente, sugere, mas é preciso afirmar, que negro não é uma categoria substancial do ponto vista de uma categoria ética e, muito menos do ponto de vista de uma categoria êmica. Segundo, devemos considerá-la como uma categoria de classificação que opera de forma contingente e relacional ao contexto social e estruturas simbólicas que se expressam objetivamente, bem como atravessada pela experiência específica do grupo que está sendo sublinhado por tal categoria. Finalmente, o modo como a categoria é agenciada pelos estudantes representa uma "abertura de um outro lugar cultural, político de enfrentamento no cerne da representação colonial” (BHABHA, 2013, p. 62), ou seja, racista, que está, evidentemente, inscrita de forma tácita na prática policial. Com efeito, podemos interpretar que o posicionamento dos estudantes não apenas inverte o quadro de representações, mas, propõe outro caminho: busca desestabilizá-lo, tratando a diferença não mais como uma fronteira entre dentro e fora, mas como um "lugar" - incerto e disputado - dentro do próprio centro, do campo das representações culturais.

Daqui em diante descrevo outras circunstâncias etnográficas recorrentes em que o sotaque é agenciado (ORTNER, 2006) enquanto estratégia étnica pelos jovens angolanos para novamente tangenciar a estrutura cultural codificada racialmente que encontraram na sociedade brasileira. Rabieth Moniz (conhecido como Matíaz) é um jovem de 29 anos que esteve no Brasil entre 20062013 e que cursava (no momento desse relato 2012) o último ano de Engenharia Ambiental. Em um diálogo corriqueiro Matíaz relata uma das circunstâncias mais constrangedoras que passou no Brasil.

Há algum tempo o Matíaz fora a uma ótica comprar uma câmera digital, chegando à loja a vendedora não o atendeu, segundo o jovem, a mesma o tratou com certo descaso e displicência. Apenas, após certo tempo e, alguns olhares de reprovação, dispôs-se a atendê-lo. Matíaz narra que, ao dizer que gostaria de uma câmera digital a vendedora lhe ofereceu quase que automaticamente o aparelho mais inferior e barato da loja. No entanto, a câmera que o jovem se interessou não era a 
inferior muito menos a mais barata. Ele interessou-se por uma câmera de alta resolução e que seu preço se aproximava $\mathrm{R} \$ 1200,00$. Hesitante, apresentou a câmera a Matíaz e sugeriu que pagasse no crediário (em várias vezes). Matíaz pagou à câmera a vista, a vendedora se espanta e lhe dá um brinde - um óculos. Narra, também, que posteriormente tratamentos como esses foram recorrentes pelos comerciantes de Lins-SP.

Narro, também, certa circunstância vivenciada, por meu interlocutor Vicente, fato ocorrido no final de 2006, ano em que chega ao Brasil. Estavam ele e uma amiga na cidade do Rio de Janeiro - RJ, Vicente não estava muito bem, com uma indisposição muito grande. Diante desse intenso mal estar, decidem ir a um hospital para que pudesse ser observado por um médico. Naquele tempo Vicente ainda estava vinculado à empresa que fomentara a sua vinda para o Brasil, assim, estava conveniado a um bom plano de saúde (UNIMED), com cobertura completa em todo país. Procuram uma farmácia nas proximidades com o intuito de pedir informação de onde poderiam encontrar uma clínica do respectivo convênio de saúde. Ao encontrar a farmácia para pedir informação de onde poderiam encontrar uma clínica, a atendente do estabelecimento oferece a eles um remédio para o mal estar de Vicente. Segundo o jovem, eles insistem novamente em saber a localização da clínica e, novamente, a atendente ofereceu outro remédio salientando que este era um genérico, com o preço mais em conta - mais barato - e, também, informou da existência de um hospital público próximo ao local.

Vicente e sua amiga continuam a frisar o seu interesse na clínica respaldada pelo seu convênio. A atendente então diz que já havia oferecido remédio mais barato e falado do hospital público. Neste momento Vicente e sua amiga exaltam-se, o que segundo ele, reflete-se em suas falas, seus sotaques transparecem, afirmam que não são brasileiros e querem ir especificamente para àquela clínica. De imediato a atendente muda o tom do discurso, dizendo que não sabia que não eram brasileiros. Vicente diz que, embora, como certa dificuldade a moça esforça-se para explicar a eles onde poderiam encontrar uma clínica da Unimed para atendê-los.

Embora, apresentem narrativas diversas, é evidente o fio que conduz e as orquestram: são formas de discriminação racial inscritas nas relações e práticas cotidianas. "Preto rico no Brasil é branco, assim como branco pobre é preto" diz o dito popular. Não se "preconceitua" um vereador negro, a menos que não se saiba que é um vereador, só se discrimina um estrangeiro igualmente negro ao menos enquanto a sua condição estiver pouco especificada (SCHWARCZ, 1998, p.182). A afirmativa dá antropóloga é esclarecedora, uma vez que sugere certa peculiaridade encerrada na 
relação - status, cor e raça, ou seja, como no Brasil a raça é uma questão de marca e de classe social, indivíduos são embranquecidos instantaneamente em função da posição e situação em que estão inseridos na sociedade.

Retomando nossas narrativas, assim como na intervenção policial, bem como o atendimento na farmácia, é especificando a sua condição de "negro estrangeiro" por meio do sotaque que os jovens produzem um efeito de diferenciação em relação aos "negros brasileiros" é subjacentemente a estrutura racista cotidiana.

\section{Prólogo}

Daquela vez, fui a Lins em uma quarta-feira (Setembro de 2012) sem avisar antecipadamente meu interlocutor. Cheguei à cidade por volta das 10:00 horas da manhã. Em um telefonema para Vicente, disse-me que estava na faculdade, assim, me encaminhei a Unilins. Na faculdade, Vicente estava na biblioteca trabalhando em sua monografia, junto com uma amiga. Nara (sua amiga), natural do interior de angola, estudante também do curso de Engenharia Ambiental, estava no Brasil desde meados do ano de 2007. Embora, eu e Vicente estivéssemos conversando muito, e eu tentando conversar com Nara, a mesma não parecia muito disposta a falar, me respondia apenas o "básico" e não muito mais. Como não havia avisado da minha ida, meu anfitrião estava despreparado, tanto que, fomos dali, almoçar na casa de uma amiga. Fomos a uma casa próxima à faculdade, onde Magna (estudante angolana de 27 anos, natural de Luanda; do curso Engenharia Elétrica) estava nos esperando para o almoço.

Já a conhecia, lembro-me de que morava no mesmo pequeno condômino de apartamentos que Vicente morava com Cícero. Lugar pequeno formado por várias kitnet's de dois quartos, cozinha e sala juntos e um banheiro, relativamente, espaçoso. Vicente me explica que Magna havia mudado do lugar anterior, todavia, Cícero e ele, continuavam a morar no mesmo lugar. Enfim, chegamos a nova casa de Magna. A estudante havia se mudado pois seu irmão mais novo, também, viera estudar no Brasil. Ela nos recebeu muito bem, dizendo lembrar-se de mim. Perguntado as quantas andava a pesquisa, digo a ela que naquele momento eu tratava de um aspecto específico da pesquisa. Explico a Magna a minha intenção de me concentrar na linguagem, especialmente no sotaque, e como este era utilizado enquanto estratégia dos jovens angolanos em Lins para tangenciar práticas racistas persistentes no cotidiano brasileiro. 
Enquanto nos encaminhávamos para a cozinha, Nara e Magna passam a conversar sobre o que lhes havia explicado. Interessante, que Nara, anteriormente, na faculdade, mostrava-se aparentemente como uma moça introvertida. No entanto, no ambiente privado, Nara muda a sua conduta, não apenas passando a conversar mais tranquilamente, como, também, opinando sobre o que eu tinha explicado.

Segundo Vicente e Magna, realmente, talvez uma das maiores dificuldades que encontraram ao chegar ao Brasil foi a comunicação. Diziam que o sotaque deles é bem diferente do nosso, mas sobretudo, encontraram grande dificuldade em lidar, inicialmente, com a metalinguagem (palavras de duplo sentido) características do português brasileiro. Como diria o sociólogo José de Souza Martins em uma palestra em que estive presente, no $8^{\circ}$ Festival Literário Internacional de Paraty - RJ, nós no Brasil, brincando, não falamos o português de Portugal, nós aqui falamos outra "coisa", algo como um dialeto. E que uma das suas características principais é a metalinguagem - o duplo sentido. É essa, de certa forma, ambiguidade de nossa fala, que marca uma diferença em relação ao português, caprichosamente literal, falado em Angola.

Narrando uma circunstância em tal problemática semântica tornou-se relevante, Nara diz que, recentemente estava no setor de assistência social da Unilins para resolver alguns problemas burocráticos relacionados a sua permanência no Brasil. Relatou-nos que estavam presentes na sala a assistente social da faculdade responsável por acompanhar os jovens no Brasil e outras funcionárias. Em um dado momento Nara solicita a assistente que "meta" o nome dela em determinada lista. Segundo Nara todas as mulheres da sala a olham com reprovação, embora não entendesse o porquê; novamente, solicita a assistente: "meta meu nome na lista!"; "mete para mim”. Os olhares de reprovação não se cessam a cada repetição, segundo Nara, eles tornam-se mais fortes. Até que a assistente explica a ela que a palavra/verbo "mete" ou "meter" no Brasil tem seu significado associado ao ato sexual, com sentido fálico. A estudantes narra que, embora tenha compreendido o duplo sentido da palavra "mete" na língua brasileira, daquele dia em diante optou por continuar a utilizar a tal verbo quando, por exemplo, é possível operar a palavra "colocar", significante que não daria margem para qualquer apropriação ambígua.

Magna, também, apresenta uma narrativa semelhante a esta, mas, dessa vez com a palavra "movimento". Segundo Magna certa vez havia feito um favor para um amigo, também, angolano e, que por acaso encontrou esse amigo na faculdade, sendo que este estava em uma roda de amigos brasileiros. Ao adentrar ao círculo, Magna cumprimenta a todos e, em especial o amigo de Angola 
e diz a ele ir a sua casa depois para fazer um "movimento", já que ela o tinha ajudado. Segundo ela, todos começaram a rir e fazer brincadeiras maliciosas entre ela e o amigo. Sem entender muito bem o que acontecia, insiste para que o amigo vá a casa dela, quando der, fazer um "movimento" com ela e se despede. Explica que apenas posteriormente, passa a compreender que, fazer um "movimento", também, tem duplo sentido no jogo de linguagem característico do nosso português. Porém, assim como Nara, Magna afirma que, a despeito desse jogo, continuará a usar a palavra "movimento" quando quer falar a um amigo ou amiga ir na casa dela fazer companhia, divertir-se, ou apenas retribuir um favor.

O nosso almoço continua, a saber, comíamos uma pasta, ravióli. Agradeço pelo almoço a Magna, então Nara vira-se para mim com um sorriso no rosto e diz: "obrigado nada, depois você terá que vir aqui, fazer um “movimento" com ela!”. E Magna por sua vez olha para mim lembrando "a definição que José Dias dera deles, "olhos de cigana oblíqua e dissimulada. Eu não sabia o que era oblíqua, mas dissimulada sabia, e queria ver se podiam chamar assim. Capitu deixou-se fitar e examinar. Só me perguntava o que era, se nunca os vira, eu nada achei extraordinário; a cor e a doçura eram minhas conhecidas"(ASSIS, 1997). Olho para Vicente e, como sempre em situações assim, estava a me observar sorrindo.

\section{Depois você tem que vir aqui fazer um "movimento" com ela: $\mathrm{O}$ riso e o risível como marcas do entre-lugares da cultura.}

Machado de Assis (1997), em "Dom Casmurro", fala dos olhos de Capitu, o que traduz muito bem a minha hesitação e incerteza naquele momento, não por quaisquer interesse romântico, mas por não conseguir decodificar o que estava acontecendo. Ante a esse esforço de compreensão, gostaria de partir de Geertz ao tratar do sentido da "piscadela" envolvendo os três garotos em seu texto a "Interpretação das culturas" quando propõe não só fazermos uma "descrição densa" da cultura, como tratar tal conceito a partir de seu caráter, essencialmente, simbólico e semiótico (GEERTZ, 2008, p. 4).

De fato, me vejo diante de uma "piscadela", no entanto, existem algumas, digamos, alterações de cor e tonalidade que estão presentes no meu texto e ausentes no texto do antropólogo. Assim, parafraseando, Geertz, Nara, Magna e Vicente poderiam ser compreendidos dessa forma, são os três garotos, e o que garante a inteligibilidade entre os três é justamente o seu pertencimento 
a um mesmo sistema simbólico. Nesse sentido, o sorriso de Magna é expressão objetiva de uma forma cultural, sua comicidade, na circunstância supracitada, como sugere Bergson (1980), nos informa sobre os processos de trabalho da imaginação humana, mais, particularmente, da imaginação coletiva e popular. O riso e o risível tratam-se de algo necessariamente cultural, o tal sorriso, a mim concedido, está inscrito dentro de um quadro de representação específico ou como Eriksen (2003) diria, operando aparentemente a partir de sistema cultural limitado e bem definido.

A minha indagação, entretanto, é que as coisas não são bem assim em meio ao meu fazer etnográfico. Se, a posição de Geertz diante da leitura textual da cultura supõe limites, fixidez, localização e implicitamente uma noção sistêmica de cultura, não são exatamente tais fronteiras que determinam o que está dentro ou fora não estão sendo tensionadas? As premissas que estabeleceriam a distinção de autoridade e inteligibilidade entre etnógrafo e nativo também não estariam sendo descentradas?

Como diria Eduardo Viveiros de Castro (2002) em seu texto "O nativo relativo" falando das regras do jogo da antropologia, aquilo que faz do nativo um nativo é a pressuposição, por parte do antropólogo, de que a relação do primeiro com sua cultura é natural, isto é, intrínseca e espontânea, e, se possível, não reflexiva; melhor ainda se for inconsciente. O nativo experimentaria sua cultura em seu discurso; o antropólogo também, mas, esse pretende ser outra coisa que um nativo, deve poder exprimir sua cultura culturalmente, isto é, reflexiva, condicional e conscientemente. Sua cultura (a do antropólog) se acha contida, nas duas acepções da palavra, na relação de sentido que seu discurso estabelece com o discurso do nativo. Já o discurso do nativo, este está contido univocamente, encerrado em sua própria cultura. $\mathrm{O}$ antropólogo usa necessariamente sua cultura; o nativo é suficientemente usado pela sua. (VIVEIROS DE CASTRO, 2002, p. 114). É essa experimentação reflexiva com a própria cultura, é essa relação, que dá ao antropólogo aquilo que Viveiros de Castro chama de vantagem epistemológica. A posição privilegiada do etnólogo está, portanto, pautada em três aspectos: primeiro, a noção de uma cultura fixa, localizada, digo do ponto de vista geográfico, de seu "lugar"; segundo, embora essencialmente semiótica, apresentando-se de forma sistêmica e holística; terceiro, classicamente, o antropólogo tem como prioridade compreender o ponto de vista do nativo, o sentido dele, mas é ele quem detêm o sentido desse sentido.

A questão é que no contexto etnográfico em que me encontro os três aspectos que descrevi não encontram relativa objetividade. Novamente: primeiro, tais estudantes estão em um contexto 
desterritorializado, para além de culturas fixas e localizadas (GUPTA \& FERGUSON, 2000, p. 43); segundo, sim, uma cultura semiótica, todavia, não holística marcada por processos de crioulização e hibridação (GILROY, 2002); terceiro, o privilégio epistemológico de explicar o sentido do sentido do nativo é questionado, declare-se a virada dialógica, é imprescindível romper com os monólogos que caracterizam as monografias antropológicas clássicas (HOFBAUER, 2009, p. 103). Elementos, todos, presentes no jogo de linguagem: "obrigado nada, depois você terá que vir aqui, fazer um "movimento" com a ela!", no sorriso e nos olhos de Magna e, do olhar capcioso e sorriso de cumplicidade de Vicente.

A descrição (a tensão entre diferentes modelos de trato da diferença) acima nos possibilita compreender o sotaque de forma específica, e a linguagem em geral, como marcadores de pertencimento operados intencionalmente enquanto estratégia étnica e, vale-se ressalvar, traço vernacular de uma identidade não essencializada. A análise ganha mais profundidade ao considerarmos o lugar que a linguagem ocupou em meio a reflexão dos intelectuais negros que preocuparam-se em investigar as relações coloniais. Fanon, por exemplo, afirmaria que:

Atribuímos uma importância fundamental ao fenômeno da linguagem. É por esta razão que julgamos necessário este estudo, que pode nos fornecer um dos elementos de compreensão da dimensão para-o-outro do homem de cor. Uma vez que falar é existir absolutamente para o outro. (FANON, 2008, p.33).

Podemos considerar que essa relação determinada por Fanon orienta fenomenologicamente a utilização do sotaque enquanto estratégia ética diante da forma específica em que o racismo apresenta-se no Brasil, é por meio dele que os jovens se diferenciam e se fazem, portanto, reconhecer para-o-outro. O sotaque comporta-se como elemento que denota a dimensão relacional da linguagem, nos conduzindo para outros dois aspectos pressentes em nossa observação etnográfica de forma acentuada, quais sejam, a relação dialógica entre "etnólogo" e "nativo", e o trato relacional do grupo com o contex to brasileiro.

Com efeito, não é necessariamente o jogo de linguagem experimentado por mim naquele momento que é objetivo desta análise, mas, como esse jogo é operado (ORTNER, 2006), e, de que forma a enunciação (BHABHA, 2011) é conduzida e, como está é possível de ser interpretada. Quando do primeiro momento da enunciação em que Nara é recriminada tanto pela assistente social e pelos presentes ao dizer: "mete", existe ali um ruído não intencional no processo de significação. Embora o significante permaneça enquanto imagem sonora, o seu significado não é inteligível, na 
medida em que está inscrito em estruturas de representação (culturas) distintas. No entanto, apesar de recriminadas, tanto Nara quanto Magna, afirmam que continuariam a se valer de "mete" e/ou "movimento" quando necessário. Não obstante, Fanon (2008) nos chama a atenção da necessidade do negro posicionar-se diante da linguagem, pois, "um homem que possui a linguagem possui, em contrapartida, o mundo que essa linguagem expressa e que lhe é implícito. Já se vê aonde queremos chegar: existe na posse da linguagem uma extraordinária potência, Valéry estava consciente disso, fazendo da linguagem o deus de carne desorientado (FANON, 2008, p. 34). Tal observação nos dá a proporção da radicalidade da utilização do sotaque e do posicionamento em relação a linguagem de Nara e Magna.

Já no segundo momento de nosso episódio, o jogo toma outro contorno também propositivo, seu novo aspecto fundamental está no "lugar" da enunciação, paradoxalmente, anterior ao texto enunciado e inscrito subjacentemente durante a fala. Tal aspecto está estreitamente ligado aos processos de inclusão, exclusão e articulação de significados semânticos durante a significação, isto é, Nara ao dizer: "obrigado nada, depois você terá que vir aqui, fazer um "movimento" com ela!"; fala de seu "lugar" (enunciação), de seu quadro de representações em que o signo "movimento" - carrega dada carga semântica específica (ou seja, uma dada relação arbitraria, e não outra, entre significante e significado). Porém, intencionalmente, com a grande contribuição do olhar e sorriso de Magna, ocorre um jogo de linguagem, que desloca o significante de seu primeiro mapa cultural. Aparentemente, a enunciação passa estar fixada a partir de outro "lugar" (o contexto cultural brasileiro), entretanto, não é isso o que acontece. Pois, se fosse esse o caso, eu, etnólogo, aquele que experimenta a própria cultura reflexivamente, poderia por assim "ler" e "interpretar" a dada circunstância etnográfica. Contudo, hesito, são "olhos de cigana oblíqua e dissimulada." Crise de significação?

Publicada em 2011, a coletânea do autor pós-colonial Homi Bhabha intitulada $O$ bazar global e o clube dos cavaleiros ingleses, traz consigo o texto "O entrelugar das culturas", onde o autor desenvolve algumas aproximações em relação a esta categoria analítica já apresentada em outra obra sua publicada no Brasil em 1998 - O local da cultura. Assim, gostaríamos de buscar uma aproximação com a noção de "entre-lugares”. Segundo Homi Bhabha, ao citar Eliot, “[...] A cultura que se desenvolve em um solo novo tem que ser, ao mesmo tempo, desconcertantemente semelhante e diversa em relação a qual é aparentada [...]. (ELIOT, apud BHABHA, 2011, p. 82). 
É esta cultura parcial, é esse tecido contaminado, que produz uma conexão entre as culturas. O resultado, segundo Bhabha, é algo que aproxima a ideia de um "entrelugar" das culturas, a um só tempo, desconcertantemente semelhante e diverso (BHABHA, 2011, p. 82). É desse "entrelugares" das culturas, é desse espaço liminar de onde provem, gostaríamos de sugerir, a enunciação de Nara, o olhar e sorriso de Magna e o olhar de Vicente. Eles não estão do lado de lá, ou do lado de cá, estão no "entrelugares", entre culturas. Não ocorreu, haja vista, uma crise de significação, mas por meio do riso, observamos a articulação da diferença, nesse caso, a linguagem, a partir daquilo que o autor chama de "terceiro espaço" que, embora irrepresentável, constitui as condições discursivas de enunciação que garantem que os significados e símbolos da cultura não tenham unidade ou fixidez primordial (BHABHA, 2013 [1998], p.68).

O fundamento que desencadeia o ruído, assegurando a não unidade e fixidez do significado, é aquilo que Bhabha chama disjunção semiótica do sujeito. Há a desestabilização da prerrogativa estruturalista da relação causal entre aquilo que se esta falando no momento presente - enunciado e/ou sujeito da proposição - e o "lugar" de onde se fala - cultural e discursivo - em relação ao tempo presente. Em outras palavras ao cindir o sujeito da enunciação, não se verificaria mais uma relação causal entre ação e estrutura (COSTA, 2006, p.93). O terceiro espaço constitui-se na mobilização dessas duas dimensões mais a implicação específica do enunciado como estratégia performativa como diferença cultural, produzindo uma quebra na sincronia da temporalidade cultural, interrogando a interpretação literal do sujeito. Agora não mais há ali um objeto da cultura (BHABHA, 2013 [1998], p.72), mas, um sujeito significante (grifo nosso) que toma a enunciação para si. Isto significa dizer que, nem Bentinho e, muito menos, eu - o etnólogo -, apesar de compreender e interpretar a cultura reflexivamente, estamos reféns do olhar de Capitu/Magna. A vantagem epistemológica do etnólogo, sua suposta autoridade cultural, desmorona.

\section{Epílogo}

Num de nossos primeiros encontros, Vicente ${ }^{15}$ (meu principal interlocutor) havia me convidado para almoçar em sua casa. Ao chegar procurei saber qual seria o cardápio, Vicente me surpreendeu: o nosso almoço seria feijoada. Imediatamente lembrei-me do texto de Peter

\footnotetext{
${ }^{15}$ Vicente, natural de Luanda, fora estudante de Engenharia Ambiental, no momento em que eu o conheci (2010) estava com 24 anos. Hoje Vicente é Engenheiro Ambiental e trabalha na Odebrecht em Angola.
} 
Fry “Feijoada e Soul Food: notas sobre a manipulação de símbolos étnicos e nacionais”. Indaguei Vicente se a escolha do cardápio (feijoada) devia-se ao fato de eu "ser negro", ou, por ser uma comida tipicamente brasileira?

Confesso que a minha expectativa era a de eu "ser negro". Porém, Vicente respondeu-me que fez feijoada por ele entender que é uma comida tipicamente brasileira. Empenhei-me em discutir com meus interlocutores o que significa pensar um prato como "comida de negro" e/ou como uma culinária tipicamente brasileira. Confesso também, que estanhei muito comer feijoada com feijão carioquinha e legumes.

Após o almoço, Vicente me conduziu por ruas próximas a sua casa. Estávamos indo para uma república que ele fez questão que eu conhecesse. Depois de alguns minutos, enfim, chegávamos à república. Fomos recebidos por um dos rapazes que residia na casa. Tratava-se de uma casa bem espaçosa com sala, copa, cozinha, três quartos e quintal, habitada por quarto homens. Dirigimo-nos logo a um dos quartos e foi lá que conheci um jovem angolano apelidado de Porcaria.

Porcaria era um jovem de 24 anos, natural de Luanda, que estava no Brasil desde 2010. Ele cursava Engenharia Civil e, a despeito de meus esforços, não consegui descobrir o seu nome completo/oficial. Ele foi me apresentado dessa forma e assim continuava o tratando/chamando. Ele estava deitado na cama, escutando pagode e conectado a uma rede social; enquanto procurava alguma festa para a qual pudesse ir naquela noite, mexendo em seu cabelo cheio de dreadlocks.

Conversávamos a respeito do que tratava a pesquisa: da minha intenção e dos meus objetivos. Conduzia o diálogo, indagando sobre a experiência migrante e a sua percepção das diferenças: sobretudo no que diz respeito à questão racial. Ele queixava-se do "sectarismo" que observava na sociabilidade brasileira e dos preconceitos que tinha sofrido desde a sua chegada. No entanto, o fato que me surpreendeu foi a sua reflexão sobre a "diferença racial". Segundo a assertiva de Porcaria, apoiada também por Vicente, "os blacks" só fazem cagada"; em qualquer lugar do mundo isso se repetiria, basta uma pequena ascensão social para que esse axioma se manifeste. Eu buscava entender melhor o que os meus interlocutores queriam dizer com isto: segundo eles, os jovens negros, que conseguem ascender socialmente, tendem a desqualificar seus velhos amigos, deixam de estudar e se tornam pessoas irresponsáveis.

Enquanto tratávamos desta reflexão aparentemente recorrente nas conversas dos próprios jovens, fomos interrompidos por um dos jovens moradores da casa. De repente, de forma súbita, intempestiva, um dos jovens residentes na casa entrou no quarto esbravejando informações sobre 
a NBA (liga de basquete norte-americana).

De imediato, Porcaria encerra nosso diálogo e concentra-se em discutir os últimos acontecimentos da liga. Neste momento a minha perplexidade foi total. O cenário me lembrava uma discussão exaltada sobre futebol entre dois torcedores de times rivais. Paralelamente, dei-me conta de que Vicente observava as minhas reações e emoções sistematicamente: ao olhar para ele, concedeu-me um sorriso e, neste momento, entendi que eu também era “objeto" de observação de meu interlocutor.

\section{Conclusão}

Como Aganben (2009) explicou-nos, aquilo que é o contemporâneo enuncia-se mediante uma ruptura em uma continuidade tida como linear e provoca desestabilização. O contemporâneo é intempestivo, seria justamente este traço que o marca. Assim, no exato momento em que o jovem angolano interrompe o diálogo que eu estabelecia com Porcaria, testemunhamos a articulação de um traço da contemporaneidade. A informação sobre a NBA adquirida pela internet representa um corte do espaço pelo tempo, produzindo, nesta nossa era da globalização, conexões instantâneas possibilitadas pelas novas tecnologias, pelos meios de comunicação e informação que se tornam fatores cada vez mais importantes nos processos de construção de identidades e culturas.

A complexidade desse conjunto de processos pode ser observada na circunstância supracitada; a diversidade de traços culturais enunciados e agenciados por Porcaria são reflexos da forma pela qual a cultura e a identidade negra tem sido historicamente produzidas na diáspora africana. Segundo Paul Gilroy, em sua obra já clássica $O$ Atlântico Negro: Modernidade e dupla Consciência (2001[1993]), se faz necessário, por exemplo, pensar a produção de uma "cultura negra" para além de particularidades nacionais, ou, em nosso caso, vernacular angolana . Continua o autor, devemos investir numa outra perspectiva analítica capaz de pensar e tratar a diferença não mais a partir de uma noção de cultura e de grupos étnicos concebidos como entidades hermeticamente fechadas, abrindo um espaço para refletirmos sobre processos de crioulização e de hibridação. Tal modelo de identidade e cultura (ou, em última analise, de diáspora africana) seria hábil, alega o autor, de rejeitar não só os esquemas epistemológicos ocidentais (suas representações normativas) quanto a estética política nacionalista e herméticas dos modelos anteriores de identidade (GILROY, 2004, p. 369).

Se levarmos as sugestões de Gilroy a sério, possivelmente, seja lícito dizer que o processo de etnicização que assistimos entre os estudantes angolanos de Lins não é apenas político (aspecto 
característico do conceito de etnicidade ${ }^{16}$ ), mas, também, epistemológico. O complexo posicionarse dos estudantes, segundo o modo como agenciam a linguagem e o sotaque, denota a constituição de uma identidade cultural que classificaríamos como diaspórica. Essa identidade diaspórica a todo momento está movimentando-se, deslocando o conjunto das matrizes normativas de representação acerca da sua experiência coletiva, seja a autoridade antropológica e/ou o racismo cotidiano brasileiro. A complexidade desse conjunto de processos pode ser observada na circunstância supracitada; a diversidade de traços culturais enunciados e agenciados por "Porcaria" são reflexos da forma pela qual a cultura e a identidade "negra" são produzidas na diáspora.

É em meio a esse contexto que a intempestiva indagação de Stuart Hall (2003) - que negro é esse na cultura negra? - ganha significado. A utilização de traços da cultura negra brasileira (pagode), caribenha (dreadlocks), americana (basquete) denotam não só a produção de figura de identidade e diferença marcadas por processos complexos, mais ou menos conscientes e intencionais de inclusão e exclusão, como nos conduz e também ao insistente e necessário descentramento da ideia de sujeito negro essencial ou substantivo. Na articulação da linguagem em geral e do sotaque, particularmente, os estudantes produzem um contraste em relação ao negro brasileiro, operando um processo de etnicização que desloca intencionalmente a significação do ser negro no processo de racialização de sua experiência coletiva. O resultado é um ruído, uma hesitação na significação que adia o significado, precisamente a différance. Esse movimento que adia o significado impede qualquer investida com pretensão a fixação está presente na negociação da linguagem. Isto marca os complexos processos culturais pelos quais os estudantes estão experimentando e ao mesmo tempo produzindo suas figuras de identidade e diferença, sujeitos e grupos que pela sua experiência não podem ser fixados enquanto objeto cultural, na medida em que tomam a enunciação para si.

Justamente por tais razões que, segundo nossa abordagem e objetivos, o conceito descentrado de diáspora africana ganha tamanha centralidade. Pois, se é verdade que processo de racialização, arbitrariamente imposto à experiência coletiva dos estudantes, os faz posicionar etnicamente, é por meio do conjunto de deslocamentos o conceito descentrado diáspora africana sugere que tal posicionamento torna-se radical. Em meio e enunciação de nossos interlocutores, nos foi possível problematizar as ideias do Estado-Nação e de identidade nacional puros, além da

${ }^{16}$ Ver: BARTH, F. Os grupos étnicos e sua fronteira; In: Teorias da etnicidade, Editora Unesp, 2011. 
própria ideia de identidade cultural integra, abrindo espaço para emergência e reconhecimento de identidades que estão em perpetuo movimento. O conceito de identidade foi colocado sob rasura, interrogando a cultura tida como fixa e localizada. São esses deslocamentos protagonizados pela noção de diáspora africana, que qualificamos como radical, impele os estudantes angolanos de Lins para um posicionamento ontológico, da negação promovida pela racialização e exigência do reconhecimento de sua atividade negadora.

\section{REFERÊNCIAS}

AGAMBEN, George. O que é contemporâneo? In: AGAMBEN, G. O. O que é contemporâneo? e outros ensaios. ARGOS, 2009.

ASSIS, Machado. Dom Casmurro. L\&PM; Edição: Edição de bolso, 1997.

BERGUSON, Henri. O riso: ensaio sobre a significação do cômico. Zahar, 1980.

BHABHA. Homi. 2013. O local da cultura. Belo Horizonte. Editora UFMG, 2013.

O entrelugar das culturas. In: $O$ bazar global e o clube dos cavaleiros ingleses. Rio de Janeiro. Rocco, 2011.

BRAH, A. Cartografías de la Diápora: Identidades encustión. Traficantes de sueños. Mapas, 2006.

COSTA, Sergio. Dois Atlânticos: teoria social, anti-racismo e cosmopolitismo. Editora UFMG. 2006.

ERIKSEN, Thomas Hylland. Crioulização e criatividade. Global Networks, [S.1.], v. 3, n. 3, p. 223-237, 2003.

FANON. Frantz. Pele negra, máscaras brancas. Salvador: EDUFBA, 2008.

FONSECA, Dagoberto José. A tripla perspectiva: a vinda, a permanência e a volta de estudantes angolanos no Brasil. Pro-Posições, Campinas, v 20, n.1 (58), p. 23-44, 2009.

GEERTZ, Cliffod. A interpretação das Culturas. Rio de Janeiro. LTC, 2008.

GILROY, Paul. O Atlântico Negro. EDITORA 34 Ltda, 2002.

. Entre campos: Nações, Culturas e Fascínio da Raça. São Paulo: Anablume, 2004. 
GUIMARÃES, Antônio Sergio. Classes, raças e democracia. São Paulo, Editora 34, 2002.

GUPTA, Akhil; FERGUSON, James. Mais além da "cultura": espaço, identidade e política da diferença. In: ARANTES, Antônio A. (Org.). O espaço da diferença. Campinas, SP: Papirus, 2000 .

GUSMÃO, Neusa Maria Mendes. África, Portugal e Brasil: um novo triângulo das bermudas? In: Cadernos Ceru, v. 23, n. 2, p. 51 - 62, 2013.

Diáspora Africana: vida de imigrantes e estudantes em Portugal e no Brasil. In: 26 Reunião Brasileira de Antropologia, 2008.

. Trajetos Identitários e Negritude: jovens africanos no Brasil e em Portugal. In: Impulso, p. 45-57, 2006.

HOFBAUER, Andreas. Entre olhares antropológicos e perspectiva dos estudos culturais e pós coloniais: consensos e dissenso no trato da diferença. In: Antropolítica. Niterói, n. 27, vol, 2, p. $99-130,209$.

Antropologia e pós-colonialismo: focando as castas na Índia. In: Ilha: Revista de Antropologia, v.19, n. 2, p. 37-71, 2017.

ORTNER, Sherry. Uma atualização da teoria da pratica. In: Conferencias e Diálogos: saberes e praticas antropológicas. $25^{\circ}$ Reunião Brasileira de Antropologia - Goiânia, 2006.

SARAIVA, José Flavio Sombra. A África e o Brasil: encontros e encruzilhadas; In: Ciências \& Letras (Revista FAPA). Edição especial nº 21/22. Porto Alegre, 1998.

. A política exterior do governo Lula: o desafio africano. In: Revista Brasileira de Politica, n. 45 , p. $5-25,2002$.

SEGATO, Rita Laura. Raça é signo; In: Série Antropologia, Brasília, 2005.

SILVÉRIO, Valter Roberto. Multiculturalismo e metamorfose na racialização: notas preliminares sobre a experiência contemporânea brasileira. In: BONELLI, Maria da Glória; LANDA, Martha Diaz Villegas (Orgs.) Sociologia e mudança social no Brasil e Argentina, São Carlos:

Compacta Gráfica e Editora, 2013.

SCHWARCZ, Lilia Moritz. "Nem preto nem branco, muito pelo contrário: cor e raça na intimidade", In: NOVAES, Fernando A.; SCHWARCZ, Lilia M. (Orgs.). História da vida privada (Vol. IV). São Paulo: Companhia das Letras, 1998.

VIVEIROS DE CASTRO, Eduardo B. O nativo relativo. In: Mana, v. 8, n. 1, 2002.

\section{DOCUMENTOS OFICIAIS}


BRASIL. Congresso Nacional. Lei no 10.639, de 9 de Janeiro de 2003. Brasília, DF, 2003.

BRASIL. Ministério da Educacão. Parecer CNE/CP n. 3, de 10 de marco de 2004. Institui as diretrizes curriculares nacionais para a educação das relações etnico-raciais e para o ensino da história e cultura afro-brasileira e africana. Brasília, DF, 2004 